\title{
Synthesis of polyurethane/clay nanocomposites based palm oil polyol coating
}

\author{
Teuku Rihayat ${ }^{1, a}$, Suryani Salim ${ }^{1,2}$, Harry Agusnar ${ }^{2}$, Fajri $^{3}$ and Zaimahwati ${ }^{1}$ \\ ${ }^{1}$ Department of Chemical Engineering, \\ Politeknik Negeri Lhokseumawe, Aceh, Indonesia \\ aEmail : teukurihayat@yahoo.com \\ Phone : 6281377166657 \\ ${ }^{2}$ Department of Chemistry, Faculty of Mathematics and Natural Science, \\ University Sumatera Utara, Medan, Indonesia \\ ${ }^{3}$ Department of Civil Engineering, Politeknik Negeri Lhokseumawe, Aceh, Indonesia
}

\begin{abstract}
In this study, we investigated the Polyurethane paint based on palm oil with the addition of nanoparticles montmorillonite as a heat-resistant. The composites with $1 \mathrm{wt} \%, 3 \mathrm{wt} \%$ and $5 \mathrm{wt} \%$ of bentonite filler content obtained by synthesizing in situ were investigated and compared to the neat polyurethane matrix material. The processing of bentonite for montmorillonite was done through several stages including: sedimentation, ultrasonication, dried, sieved with a 200 mesh sieve, then characterized. Untreated MMT were isolated and modified with CTAB. The addition of MMT into polyurethane, as much as $5 \% \mathrm{wt}$, can increase the heat as evidenced by the TGA test. The TGA results indicated an enhanced thermal stability, as compared to the neat polyurethane. The onset degradation of neat polyurethane and weight reduction began at a temperature of 50$150^{\circ} \mathrm{C}$ and completely decomposed at the temperatures of $380^{\circ} \mathrm{C}$ and for PU MKS-MMT reduction, the initial weight started at a temperature of $150-200^{\circ} \mathrm{C}$ in $5 \% \mathrm{wt}$ and decomposed in the end at a temperature of $490^{\circ} \mathrm{C}$. In this research, we also tested the gloss adhesive polyurethane with the addition of MMT; the result stated that the addition of 5\%wt MMT can improve the adhesion of polyurethane. The addition of MMT in polyurethane can also enhance the gloss polyurethane compared with polyurethane coated without the addition of MMT.
\end{abstract}

Keywords: Polyurethane, Montmorillonite, Polyols, Thermal.

\section{INTRODUCTION}

Polyurethane is a polymeric material containing the functional groups urethane (NHCOO-) in the main chain, and urethane groups formed from the reaction between isocyanate group with a hydroxyl group $[1,2]$. Polyurethanes is a polymeric material that is very easy to set up for a variety of applications. The application of polyurethane is extremely varied and diverse; polyurethane can be produced as foams, elastomers, plastics, adhesives and surface coatings for materials [3-5]. In carrying the polymer industry, it needs a worldwide total polyol of 4.85 billion tons per year and this total is expected to continue to rise. Today, nearly $95 \%$ of the raw materials for manufacture are derived from the results of refined petrochemical industry. The world's polyurethane market is used for the applications of coatings, adhesives, sealants, and elastomers. Polyurethane use very is high at $44 \%$ of the coating paint application. In Indonesia, the 
needs for polyurethane is predicted to be 35 thousand tons per year in 2014, in which the needs of polyurethane include polyol, which is met through imports from abroad [6].

Indonesia is the largest palm oil producer in the world. In 2010, Indonesia surpassed Malaysia's capacity as the next major producer of the world's palm oil [7]. Palm oil contains $45-60 \%$ unsaturated double bond group, so that at a certain temperature and pressure with the aid of a catalyst. it allows the epoxidation reaction that produces palm oil epoxy. Epoxy palm oil can be used as a polyol and as raw material of polyurethane via the epoxidation and hydroxylation reactions [8-10]. Since the initial studies conducted by the discovery of polyurethane [PU] in 1937 by Otto Bayer and his coworkers at the laboratories of I.G. Farben in Leverkusen, Germany [11], a new generation of sustainable polyols has just been born. PU is obtained by the reaction of an oligomeric polyol and a diisocyanate. All these raw materials are petroleum based; now synthesized from renewable polyol such as castrol oils [12, 13], corn oil [14], wheat [15], palm [16], etc. This paper describes the effects of the syntheses of polyurethane based palm oil polyol by adding montmorillonite (MMT) to increase the thermal properties of the materials.

\section{EXPERIMENTAL METHODS}

\section{Materials}

4,4-diphenylmethane diisocyanate (MDI) was purchased from Merck and used without further purification. Bentonite of northern Aceh - it is a $\mathrm{Na}^{+}$type montmorillonite, with a cation exchange capacity of $119 \mathrm{meq} / 100 \mathrm{~g}$, dibutyltin dilaurate (pure grade, $>90 \%$ ) was supplied by the Energy Chemical (Shanghai,China), polyol based on palm oil (patent application no. PI20043190, used materials i.e. : palm oil based oleic acid ; glycerol, systerm ; 4-dodecylbenzenesulfonic acid, fluka ; extruded 3A molecular sieve, Aldrich), 1.4-butanediol (1,4-BDO, Fluka), cetyltrimethyl ammonium bromide (CTAB, Fluka), octadodecylamine (ODA, Merck) and dimethylformamide (DMF, 99\%, Fisher) were used as a solvent. Other inorganic and organic materials that were used in this study were obtained from commercially available sources, such as : Sulfuric Acid $\left(\mathrm{H}_{2} \mathrm{SO}_{4}\right.$, Merck), Natrium Chlorid ( $\mathrm{NaCl}$, Merck), Ethyl Alcohol $\left(\mathrm{C}_{2} \mathrm{H}_{5} \mathrm{OH}, 95 \%\right.$, Systerm), Dioxane (Mallinckrodt), titanium dioxide, MF resin, epoxy resin, n-butanol, barytes, silica, solvent CIX (nine carbon containing hydrocarbon) and urea formaldehyde (UF) resin that were obtained from commercially available sources and used without further purification. The outline of the stages of the study include: 1) the epoxidation of palm oil followed by hydroxylation to produce polyol palm oil along with testing, 2) the preparation of bentonite into montmorillonite, then organoclay, along with the characterization, 3) the manufacture of polyurethane by polymerizing polyol with methylene diisocyanate and its characterization 4) the manufacture of surface coating (paint) and the characterization.

\section{Synthesis of polyol based on palm oil}

The experiments were carried out in a $250 \mathrm{ml}$ three-necked flask fitted with a mechanical stirrer and a cooling system was placed with the palm oil based oleic acid, glycerol, dodecylbenzene sulfonic acid (DBSA), and an extruded 3A molecular sieve. The temperature was set to $70^{\circ} \mathrm{C}$. The reaction was continuous for $3 \mathrm{~h}$ and cooled. After the filtration was done to remove the molecular sieves, the reaction mixture was washed with a solution of sodium chloride to remove the excess glycerol. The purity of the sample was collected and characterized by FTIR and GPC. The preparation of polyol (esters) from palm oil based oleic acid and glycerol was monitored by FTIR spectroscopy. Figure 1 
shows a stretching vibration of $\mathrm{C}=\mathrm{C}$ at $1653 \mathrm{~cm}^{-1}$ and $\mathrm{C}-\mathrm{H}$ unsaturation at $3009 \mathrm{~cm}^{-1}$. The $\mathrm{O}-\mathrm{H}$ vibration frequency was between 3370 and 3470, which was about 3384.90, which meant that the molecular weight (MW) of polyol was obtained by using gel permeation chromatography (GPC) and the result was about 950. The MW value was vital in the synthesis of PU, i.e., the isocyanation process between polyol, MDI and 1,4-BDO.

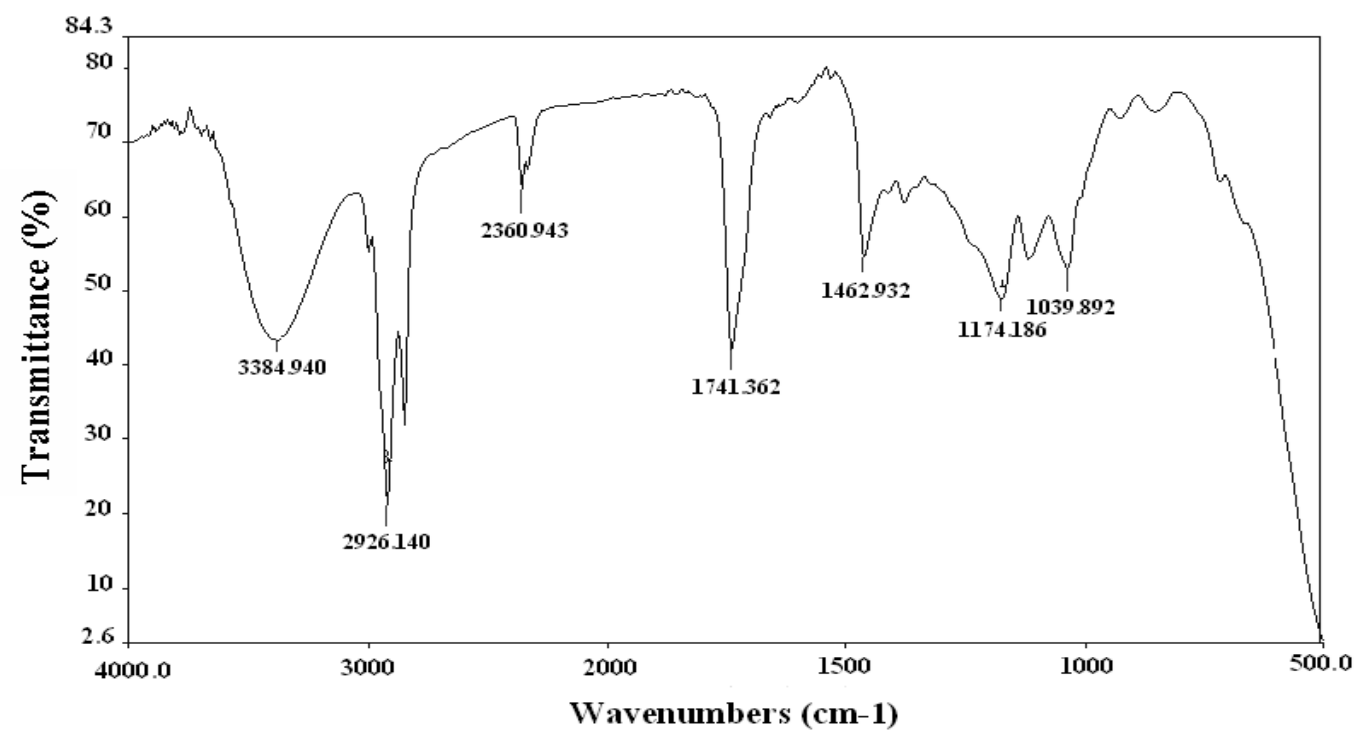

Figure 1. The FTIR spectra of the synthesized polyol based on palm oil.

\section{Bentonite processing into montmorillonite}

Bentonite was taken from the village of Muara Batu Teupin Reusep, in the Northern Aceh district. The bentonite was crushed, sieved with a 200 mesh sieve, dried at $105^{\circ} \mathrm{C}$ until dry and stored in a desiccator. Further fractionation of samples was carried out to obtain a pure MMT. The bentonite fractionation method was done by sedimentation. Bentonite suspension was done by weighing as much as 40 grams of bentonite and put in $2 \mathrm{~L}$ of distilled water. Bentonite suspension was subsequently given ultrasonic waves for 15 minutes with a $750 \mathrm{Watt}$ power at room temperature. The suspension was allowed to stand at a flat place and kept away from vibration. The sediment collected by pouring the suspension was drifted into another container and the filtrate was allowed to stand again. The precipitate that occurred was taken again by the way of pouring. A fraction that drifted back was stirred with a stir bar, then allowed to stand, where the precipitate formed within 1 week and the water evaporated. This fraction was dried in an oven at $105^{\circ} \mathrm{C}$ for 3 hours, then crushed to the size of 200 mesh where sieve grain can pass. These fractions were stored in a desiccator, and then was identified with the FT-IR, diffraction X and SEM.

\section{Modification of montmorillonite-CTAB}

0:05 mol (18.2 grams) of trimeyl cetyl ammonium bromide (CTAB) was diluted with 250 $\mathrm{ml}$ of distilled water in a $500 \mathrm{ml}$ glass beaker. This solution was then heated at $80^{\circ} \mathrm{C}$ for 1 hour. Separately, 20 grams of MMT was dissolved in $250 \mathrm{ml}$ of distilled water in a 1000 $\mathrm{ml}$ glass beaker. Further dispersion of MMT was added to a solution of CTAB solution and stirred for 1 hour. It was then filtered, washed with distilled water montmorillonite 
and continued until there were no chloride or bromide present. The MMT was put in an oven at a temperature of $60^{\circ} \mathrm{C}$ for 36 hours and then was analyzed for FT-IR and XRD.

\section{Synthesis of Polyurethane Coating Paint}

The manufacture of polyurethane film followed the procedure of making modifications of polyurethane [17]. A number of palm oil polyol was mixed with organoclay in the mixing container and set at room temperature for 10 minutes to obtain a homogeneous mixture, then isocyanate (MDI) was added and stirred for another 5 minutes until the mixture was homogeneous. Then, ABS plastic was applied to the specimen that was prepared. The results of the test panel allowed it to stand at room temperature to evaporate the solvent. A layer of polyurethane films on the metal panel were tested for gloss and adhesion.

\section{RESULTS AND DISCUSSION}

\section{Results of the polyol compound of palm oil.}

The epoxide palm oil produced had a younger color from the color of palm oil oleic acid. The iodine number analysis and oksirana to epoxide palm oil oleic acid is shown in Table 1.

Table 1. The results of the analysis of palm oil and the epoxide MKS.

\begin{tabular}{ccc}
\hline Parameter & As.Oleat MKS & Epoxide of MKS \\
\hline Iodine number $\left(\mathrm{I}_{2} / 100 \mathrm{~g}\right)$ & 56,72 & 54,29 \\
Number of peroxide $(\%)$ & 0,64 & 7,12 \\
\hline
\end{tabular}

Iodine palm oil oleic acid $56.72 \mathrm{~g} \mathrm{I} / 100 \mathrm{~g}$ decreased from $54.29 \mathrm{I} 2$ to $100 \mathrm{~g}$, and oksirana numbers increased from $0.64 \%$ to $7.12 \%$. The decrease in number of the iodine identified the oxidation processes of bonding double, while the number indicated the ring oksirana epoxides as the oxidation of the double bond contained in the oleic acid oil palm oil. The reaction formation of the epoxide compounds in vegetable oils was done [18]. Epoxides were formed from an intermediate compound that can react further to form the compound diol in the presence of nucleophiles. The density for the palm oil polyol synthesis results was obtained at 0.912 . The results of the FT-IR spectroscopic analysis of the epoxide compounds was obtained to detect the peak shift which can be attributed to the process where the reaction occurred. The spectrum at $1050.16 \mathrm{~cm}^{-1}$ region and $1014.06 \mathrm{~cm}^{-1}$ showed the $\mathrm{CO}$ bond in the epoxy ring of the epoxide compound palm oil that occurred in the reaction process.

Polyol of palm oil oleic acid which occurred at the early stage early formed an intermediate epoxide compound, through the reaction between unsaturated hydrocarbons palm oil with formic acid. The results of the FT-IR analysis showed the formation of hydroxyl groups on the palm oil epoxide compound. The the reaction took place for 5 hours at a temperature of $60{ }^{\circ} \mathrm{C}$ as evidenced by the uptake of numbers for the wave widened at $3396.18 \mathrm{~cm}^{-1}$. The hydroxy group formed was a hydroxy group at the secondary $\mathrm{C}$ atom (Table 2 ). The main region of interest in the study was the $\mathrm{C}=\mathrm{O}$ Ester absorption peak at $1708 \mathrm{~cm}^{-1}$, which was due to the esterification reaction to build polyol. The polyol was conjugated with hydrogen bonding that was constituted as the proton donor and the oxygen in carbonyl of the hard segment and in ether linkages acted as the soft segment. The formation of hydrogen bonding by the $-\mathrm{C}=\mathrm{O}$ group can be determined 
by examining the peak position at $1709 \mathrm{~cm}^{-1}$ for hydrogen bonded $-\mathrm{C}=\mathrm{O}$ and at $1731 \mathrm{~cm}^{-}$

${ }^{1}$ for free $-\mathrm{C}=\mathrm{O}$. Almost similar results were reported by Teuku and Suryani [19].

Table 2. Wave number with suspected compound.

\begin{tabular}{cccc}
\hline Functional group & \multicolumn{3}{c}{ Wavenumber $\left(\mathrm{cm}^{-1}\right)$} \\
\cline { 2 - 4 } & MKS & Epoxide & Polyol \\
\hline OH & & & \\
$-\mathrm{CH}_{3}$ & $3009,062923,73$ & 1056,$16 ; 1014,06$ & 2925,$85 ; 2855,3$ \\
& 2854,31 & & \\
$\mathrm{C}=$ O Ester & 1708,55 & 1709,56 & 1729,10 \\
C-H Alkanes & 1459,$12 ; 1412,45$ & 1410,$35 ; 1378,06$ & 1457,$75 ; 1438,18$ \\
& & & 1370,4 \\
C-H Alkanes & 935,$39 ; 722,58$ & - & - \\
C-O eter & - & 1050,$16 ; 1014,56$ & - \\
C-O Alcohol & - & - & $1029 ; 1243,2$ \\
\hline
\end{tabular}

\section{Morphology Characterization}

Based on the results of the characterization of the morphology of the surface with SEM, the surface structure of bentonite in Figure 2 and montmorillonite in Figure 3 had different surfaces; the surface of montmorillonite was more homogeneous than the bentonite surface. The montmorillonite structure was almost like a standard structure of the montmorillonite surface. From both of the Figures, morphological observations on the fractured surfaces of the PU and PU/clay nanocomposites samples are shown. The filler employed as reinforcements for polymers and resins were invariably coated with sizing the resin on whose role it was to protect them during handling and impregnation. These results were similar with observations done by Zhao el al. [20].

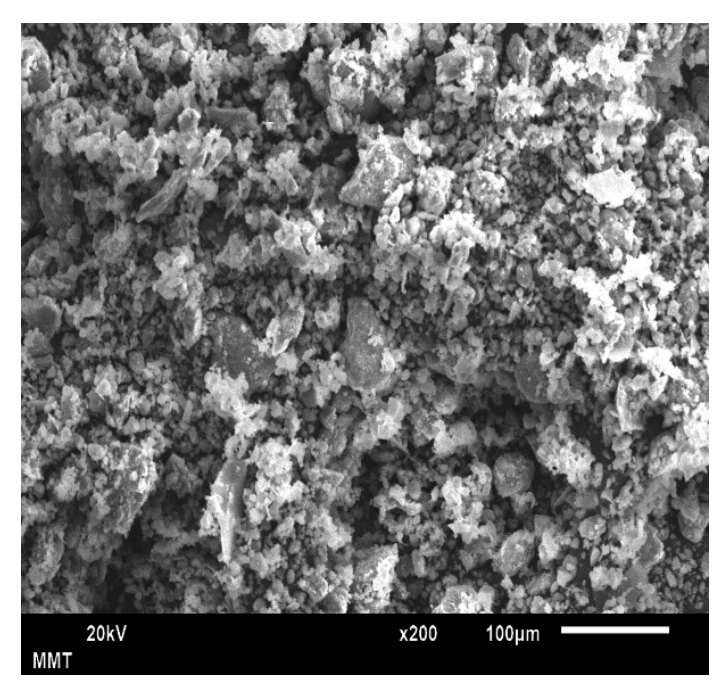

Figure 2. SEM micrograph of Bentonite

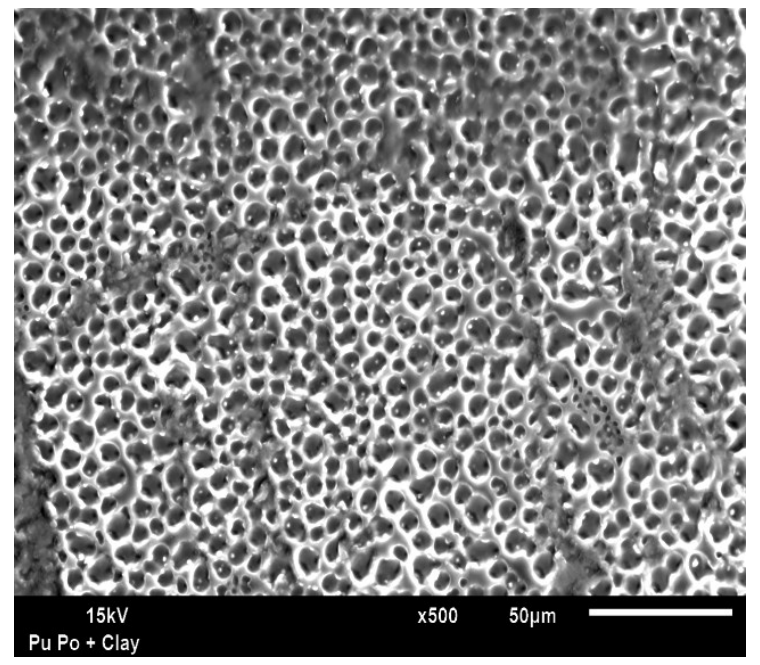

Figure 3. SEM micrograph of the isolated MMT

\section{Characterization for the Classification Adhesive Properties of the Speciment}

In Table 3, it shows that the commercial PU and PU-MKS entry in classification 2 stated that the steel spesiment applied with PU and PU-MKS had a commercial decay rate of 
about $15 \%$. Spesiment steel applied with PU-MKS-MMT was classified as 1; this stating the extent of damage for PU-MMT MKS, which was approximately 5\% (ISO 2409). The addition of MMT on palm oil-based polyurethane can strongly increase adhesion. Polyimide coating adhesive strength with the addition of 3\% clay can be increased with adhesive polyimide coatings without clay.

Tabel 3. Classifications of adhesive properties of steel spesiment applied.

\begin{tabular}{clc}
\hline No & \multicolumn{1}{c}{ Speciment } & Classification \\
\hline 1 & PU Commercial & 2 \\
2 & PU-MKS & 2 \\
3 & PU-MKS-MMT & 1 \\
\hline
\end{tabular}

\section{CONCLUSIONS}

Palm oil oleic acid by the reaction of epoxidation and hydroxylation, with the addition of $-4,4$ methylene difenil diisocyanat and with the addition of MMT, was successfully synthesized to form polyurethane / nanocomposites paint. In this research, the decomposition commercial of PU occured at $380^{\circ} \mathrm{C}$ while the MKS with the addition of MMT with $5 \%$ decomposition occured at a temperature of $490^{\circ} \mathrm{C}$. In another result, with the addition of MMT, it can improve adhesion on polyurethane paints and coatings applications can also improve the glossiness of the surface on the application. The results proved that thermal resistances were enhanced in the presence of clay, compared to pure PU. The morphology of PUs filled with MMT which was modified was found to be more intercalated in a matrix polymer, compared to a pristine PU. The results indicated that there were more significant changes in the particles of MMT after the treatment with the surfactant for the organophilic clay.

\section{ACKNOWLEDGEMENTS}

The authors express their gratude and thanks to the Kemenristek-Dikti for Financial Support through the grant No 081/PL20/R8/SP2-STRANAS/PL/2015.

\section{REFERENCES}

[1] Ahmad R, Hamidin N, Ali U, Abidin C. Characterization of bio-oil from palm kernel shell pyrolysis. Journal of Mechanical Engineering and Sciences. 2014;7: 1134-1140

[2] Charlon M, Heinrich B, Matter Y, Couzigné E, Donnio B, Avérous L. Synthesis, structure and properties of fully biobased thermoplastic polyurethanes, obtained from a diisocyanate based on modified dimer fatty acids, and different renewable diols. European Polymer Journal. 2014;61:197-205.

[3] Chiorcea-Paquim A-M, Diculescu VC, Cervini P, Cavalheiro ETG, Brett AMO. Graphite-castor oil polyurethane composite electrode surfaces-AFM morphological and electrochemical characterisation. Journal of Electroanalytical Chemistry. 2014;731:172-8.

[4] Alaa MA, Yusoh K, Hasany SF. Pure polyurethane and castor oil based polyurethane: synthesis and characterization. Journal of Mechanical Engineering and Sciences. 2015;8:1507-15. 
[5] Shan CW, Ghazali MI, Idris MI. Improved Vibration characteristics of flexible polyurethane foam via composite formation. International Journal of Automotive and Mechanical Engineering. 2013;7:1031-42.

[6] Gatto M, Wollni M, Qaim M. Oil palm boom and land-use dynamics in Indonesia: the role of policies and socioeconomic factors. Land Use Policy. 2015;46:292303.

[7] Gurunathan T, Mohanty S, Nayak SK. Isocyanate terminated castor oil-based polyurethane prepolymer: Synthesis and characterization. Progress in Organic Coatings. 2015;80:39-48.

[8] Taufik RS, Adibah M NF, Muhamad MR, Hasib H. Feasibility study of natural fiber composite material for engineering application. Journal of Mechanical Engineering and Sciences. 2014;6:940-8..

[9] Ibrahim MS, Sapuan SM, Faieza AA. Mechanical and thermal properties of composites from unsaturated polyester filled with oil palm ash. Journal of Mechanical Engineering and Sciences. 2012;2:133-47.

[10] Then YY, Ibrahim NA, Zainuddin N, Ariffin H, Wan Yunus WMZ, Abd Rahman MF. Effect of electron beam irradiation on the tensile properties of oil palm mesocarp fibre/poly(butylene succinate) biocomposites. International Journal of Automotive and Mechanical Engineering. 2014;10:2070-80.

[11] Jeenpadiphat S, Tungasmita DN. Esterification of oleic acid and high acid content palm oil over an acid-activated bentonite catalyst. Applied Clay Science. 2014;87:272-7.

[12] Kong X, Liu G, Curtis JM. Novel polyurethane produced from canola oil based poly (ether ester) polyols: Synthesis, characterization and properties. European Polymer Journal. 2012;48:2097-106.

[13] Kowalczyk K, Łuczka K, Grzmil B, Spychaj T. Anticorrosive 2K polyurethane paints based on nano-and microphosphates with high dispersing additive content. Progress in Organic Coatings. 2013;76:1088-94.

[14] Li K, Shen Y, Fei G, Wang H, Li J. Preparation and properties of castor oil/pentaerythritol triacrylate-based UV curable waterborne polyurethane acrylate. Progress in Organic Coatings. 2015;78:146-54.

[15] Martínez MM, Pico J, Gómez M. Effect of different polyols on wheat and maize starches paste and gel properties. Food Hydrocolloids. 2015;44:81-5.

[16] Mas'ud ZA, Sugita P. Synthesis and application of jatropha oil based polyurethane as paint coating material. Makara Journal of Science. 2012; 16(2):134-140.

[17] Rihayat T, Suryani S, Zaimahwati X. Preparation and properties and application of renewable source (palm oil polyol) based polyurethanes coatings and its thermal stability improvement by clay nanocomposites. Advanced Materials Research. 2014; 887-888:566-9.

[18] Septevani AA, Evans DA, Chaleat C, Martin DJ, Annamalai PK. A systematic study substituting polyether polyol with palm kernel oil based polyester polyol in rigid polyurethane foam. Industrial Crops and Products. 2015;66:16-26.

[19] Teuku R, Suryani A. Morphology properties of polyurethane/clay nanocomposites base on palm oil polyol paint. Advanced Materials Research. 2013; 647:701-4.

[20] Zhao Y, Xu J, Xie X, Yu H. An integrated environmental impact assessment of corn-based polyols compared with petroleum-based polyols production. Journal of Cleaner Production. 2014;68:272-8. 